Table 2

Values of $\mathbf{d}^{\prime}$

\begin{tabular}{lccc}
\hline & \multicolumn{3}{c}{ Study Group } \\
\cline { 2 - 4 } Type of Test & 1 & 2 & 3 \\
\hline $\begin{array}{l}\text { Yes-No } \\
\begin{array}{l}\text { Forced-Choice, } \\
1 \text { Distractor }\end{array}\end{array}$ & .65 & 1.14 & 1.21 \\
$\begin{array}{l}\text { Forced-Choice, } \\
3 \text { Distractors }\end{array}$ & .66 & 1.12 & 1.38 \\
$\begin{array}{l}\text { Forced-Choice, } \\
5 \text { Distractors }\end{array}$ & .76 & 1.23 & 1.53 \\
\hline
\end{tabular}

for the variable "number of study presentations" is significant, however $[F(2,56)=50.20 ; p<.0001]$. Thus, this analysis indicates that $\mathrm{d}^{\prime}$ increases with the number of presentations of words for study, and it does not permit us to reject the hypothesis that $\mathrm{d}^{\prime}$ remains constant as the type of test is varied.

Since no significant change in $d^{\prime}$ over various methods of test is found for any of the study groups, the mean $\mathrm{d}^{\prime}$ computed over all types of test for words in a given study group should suffice to represent sensitivity to words in that group. This mean $d^{\prime}$ was used to predict the probability of a correct response on each type of forced-choice test, and, together with the false alarm rate, it was used to predict a hit rate on yes-no tests for words of each study group. Table 1 presents these predicted probabilities. A chi square test was used to determine the goodness-of-fit of the model under the mean $d^{\prime}$ condition. For this chi square, computed over correct and incorrect responses for all types of tests and all three study groups, the value was 17.12 with $9 \mathrm{df}$ $(p=.048)$. This chi square value indicates that the model does not provide a satisfactory fit to the data. However, its significance is marginal, so that again no strong conclusion can be reached about the constancy of $d^{\prime}$ over test type.

The ambiguous nature of the results of the two statistical analyses necessitated the use of further tests of the prediction that $d^{\prime}$ is unaffected by the type of test. To clarify the results of these tests, three one-way analyses of variance were performed. The purpose of these analyses was to test for significant differences in $d^{\prime}$ corresponding to differences in the type of test, under each of the three reinforcement conditions. The $\mathrm{F}$ obtained was not significant for words in Study Groups 1 and $2[\mathrm{~F}(3,112)=.75$; p $>.50 ;$ and $F(3,112)=1.59 ; \mathrm{p}<.25]$; however, a significant $F$ was found for words in Study Group $3 \quad[\mathrm{~F}(3,112)=3.09$; $\mathrm{P}<.05]$. Thus, in the three-reinforcement condition there are significant changes in $\mathrm{d}^{\prime}$ as the type of recognition test varies. Moreover, the values of $F$ obtained by these one-way analyses increase with the number of reinforcements.

These results thus provide an indication that the TSD model begins to break down as the number of reinforcements increases. They suggest that when words are presented once or twice, the mean $d^{\prime}$ over test conditions is an adequate measure of sensitivity. However, in the case of three reinforcements, it is not possible to represent sensitivity by a single $d^{\prime}$ value which will holu up over varying types of test.

\section{REFERENCES}

BERNBACH, H. A. Decision processes in memory Psychological Review, 1967, 74, 462-480.

ELLIOTT, P. B. Tables of $d^{\prime}$. In J. A. Swets (Ed.), Signal detection and recognition by human observers. New York: Wiley, 1964 Pp. 651-684.

KINTSCH, W. Memory and decision aspects of recognition learning. Psychological Review, 1967, 74, 496-504.

UNDERWOOD, B. J., \& SCHULZ, R. W. Meaningfulness and verbal learning. Philadelphia: Lippincott, 1960.

WICKELGREN, W. A., \& NORMAN, D. A. Strength models and serial position in short-term recognition memory. Journal of Mathematical Psychology, 1966, 3, 316-347. NOTE

1. This research was supported in part by the National Aeronautics and Space Administration, Grant No. NGR-05-020-244.

\title{
Vocalizing choice prior to responding hinders discrimination learning'
}

\begin{abstract}
STEPHEN L. CARMEAN and CHRISTINE R. BAUMAN, Western Washington State College, Bellingham, Wash. 98225
\end{abstract}

Experiments with both children and adults replicated earlier findings that vocalizing choice before responding resulted in significantly more errors than vocalizing choice after responding. The difference appeared to be due to poorer performance with prior vocalization rather than to better performance with subsequent vocalization.
It was observed in two previous experiments (Carmean, 1969) that Ss, vocalizing their choices in a discrimination learning task, learned more slowly when vocalization was made before, rather than after, responding. This finding was contradictory to the prediction that vocalization before responding should be more effective, if there were any difference at all, because it would cause $S$ to inspect the stimuli more closely before responding.

The two studies reported here were run to replicate this finding and to test two subsidiary hypotheses. One of the previous experiments had used 9-year-old children as Ss, while the other had used adults. In the adult experiment, as in one previously reported (Carmean \& Weir, 1967), there was little difference between the group vocalizing after responding and a nonvocal control group, although both made significantly fewer errors than the group vocalizing before responding. In the child experiment, however, the group vocalizing after responding made significantly fewer errors than either th: group vocalizing before responding or the nunvocal control group. A nonvocal control group was included in Experiment 1 in an attempt to replicate this finding. Also, since the lack of difference th adults seemed to indicate an interaction with age, even younger children were used in Experiment 1 in order to magnify the effect.

In Experiment 2, an additional condition was added to test delay of knowledge of resul., as a possible explanation for the poorer performance with prior vocalization. The most obvious difference between the two conditions was that with vocalization before responding, a brief period of time (approximately $.7 \mathrm{sec}$ ) passed before $\mathrm{S}$ knew whether he had vocalized a correct or an incorrect name. Despite the generally accepted assumption (Deese \& Hulse, 1967; Hall, 1966) that small delays of knowledge of results are not important with human Ss, it was felt that the possibility that number of errors was a direct function of the amount of elapsed time before feedback was worth checking. This was done by increasing the delay to $4 \mathrm{sec}$ for one group of Ss to see if this would be accompanied by a further increase in errors.

\section{METHOD \\ Experiment 1}

Children in the first grade (mean age $=$ 7.16 years, $\mathrm{SD}=.51$ ) in Bellingham public schools served as $\mathrm{Ss}$. There were a total of 60 Ss; 20 in each of the three conditions (vocalize choice before responding, vocalize choice after responding, and nonvocal control). Placement in a condition was determined by simple rotation according to order of appearance, with the teachers being allowed to send the children in whatever order was most congruent with the class schedule.

With the exception of the set of stimuli used and the manner of responding, the apparatus and procedure were the same as that previously described (Carmean, in press). Pairs of line drawings of common animals (cow-cat, bear-deer, lion-rabbit, horse-pig, and elephant-giraffe) were presented, one pair at a time, by means of two readout projection units. $S$ made his response by pushing one of two buttons located just below the readout units. The 
Table 1

Mean Errors

\begin{tabular}{|c|c|c|c|c|c|c|}
\hline Experiment & $\mathbf{N}$ & $\begin{array}{l}\text { Age } \\
\text { of } \\
\text { Ss } \\
\end{array}$ & $\begin{array}{c}\text { Vocalization } \\
4 \text { Sec Before } \\
\text { Response }\end{array}$ & $\begin{array}{c}\text { Cond } \\
\text { Vocalization } \\
\text { Just Before } \\
\text { Response }\end{array}$ & $\begin{array}{l}\text { Nonvocal } \\
\text { Control }\end{array}$ & $\begin{array}{c}\begin{array}{c}\text { Vocalization } \\
\text { After } \\
\text { Response }\end{array} \\
\end{array}$ \\
\hline $\begin{array}{l}1 \\
2\end{array}$ & $\begin{array}{l}60 \\
75\end{array}$ & $\begin{array}{l}7 \text { years } \\
\text { adult }\end{array}$ & 13.0 & $\begin{array}{l}21.1 \\
14.3 \\
\end{array}$ & 15.9 & $\frac{17.2}{10.4}$ \\
\hline $\begin{array}{l}\text { Carmean \& Weir, } 1967 \\
\text { Carmean, 1969, }\end{array}$ & 44 & adult & & & 14.0 & 14.5 \\
\hline $\begin{array}{r}\text { Experiment } A \\
\text { Carmean, 1969, }\end{array}$ & 68 & adult & & 23.0 & 16.4 & 16.3 \\
\hline Experiment B & 114 & 9 years & & 18.3 & 17.7 & 14.0 \\
\hline
\end{tabular}

Means within the same experiment which are not underscored by the same line are significantly different at the .01 level by Duncan's Range Test.

task was self-paced, and choice of a correct stimulus was indicated by the sounding of a single-tone door chime.

All Ss were given pretraining with an additional pair of stimuli (monkey-dog) before starting the experiment. If they did not make three consecutive correct responses within the first 10 trials, E began giving hints and continued pretraining until the three-response criterion was met.

General instructions were the same as those quoted by Carmean (in press), and, as in that study, E reminded $S$ after the first 5 trials and every 15 trials thereafter that he was to try to choose the animals which would sound the chime. Ss in vocalization conditions were instructed to "Tell me the name of the animal that you are going to pick before you push the button" or "After you push one of the buttons, tell me the name of the animal that you picked." Noncorrective procedure was used, and the experiment was terminated after two successive errorless 5 -trial blocks or 60 trials, whichever came first.

\section{Experiment 2}

Subjects were taken from the introductory psychology classes at Western Washington State College. A total of $78 \mathrm{Ss}$ were used. There were three groups (vocalize choice $4 \mathrm{sec}$ before responding, vocalize choice just before responding, and vocalize choice after responding) with $25 \mathrm{Ss}$ in each; data from 3 Ss were discarded because of equipment failures.

The general apparatus and procedure have been described by Carmean \& Weir (1967) and Carmean \& McLachlan (1967). It was quite similar to that used for children with pairs of animal pictures being presented by projection, responses being made by pushing buttons, and knowledge of results being given by the sounding of a door chime following correct responses. The major differences were that: 10 pairs of stimuli were used instead of the 5 used for children, there was a 4-sec interval following the response before the stimuli were removed and the next pair presented, and a green light was added above the stimuli to indicate to Ss in the 4-sec condition when sufficient time had elapsed following their vocalization. The timer controlling the light was activated by $\mathrm{E}$ as $\mathrm{S}$ made his vocalization. The light did not appear for $S s$ in the other two conditions. Noncorrective procedure was used with the experiment being terminated following two successive errorless 10-trial blocks, or a total of 120 trials.

\section{RESULTS AND DISCUSSION}

Results of Experiments 1 and 2 are presented in Table 1. The error terms for the Duncan Range Tests were taken from the between sections of analyses of variance in which trials were treated as the within variable. For the sake of comparison, results from the Carmean (1969) and the Carmean \& Weir (1967) studies are also summarized in this table. It should be noted that comparable groups of children and adults cannot be directly compared with one another since the adult task contained twice as many stimuli as that used with children and up to twice as many trials were given.

Negative results were found with respect to both of the subsidiary hypotheses. The significant difference between the group vocalizing after responding and the nonvocal control group was not replicated in Experiment 1, suggesting that the difference between these conditions found in the Carmean (1969) study was probably a sampling error rather than an indication of a genuine age interaction. Also, increasing the delay between the vocalization and the knowledge of results in Experiment 2 did not result in a further increase in errors.

However, in both Experiments 1 and 2, the groups naming their choice before responding made significantly more errors than the groups naming their choice after responding. This replicates the previous results and seems to indicate that the effect is genuine. Carmean \& Weir (1967) have offered a general explanation of the effects of vocalization which can account for the poorer performance with verbalization of choice, al though it does not predict the lack of effect when the vocalization was subsequent to the response.

They suggested that on later trials $S$ tends to recall what he has verbalized on earlier trials but that he does not remember well whether the verbalized name was of a positive or a negative stimulus. They demonstrated that performance was improved when consistency was introduced into the pattern of verbalizations by having $S$ verbalize only positive stimuli and that performance worsened when heterogeneity was maximized by having $S$ verbalize positive and negative stimuli with equal frequency throughout the task. Since S must guess on the first exposures of the stimuli and will, on the average, choose equal numbers of positive and negative stimuli due to chance, his verbalizations should be a handicap-at least early in the experiment. Although additional assumptions have been considered which would allow this explanation to handle the lack of effect with vocalization after responding, all of the assumptions considered to date would be cumbersome and without logical force, and we prefer to leave this question open at present.

\section{REFERENCES}

CARMEAN, S. L. Silent children learn two-choice discriminations faster without correction. Presented at the 1969 joint meeting of the Oregon and Washington State Psychological Associations, Gearhart, Oregon.

CARMEAN, S. L. Effects of pattern of auxiliary activity on discrimination learning of children. Child Development, in press.

CARMEAN, S. L., \& McLACHLAN, J. C. Visual discrimination learning: Interactions of auditory input pattern, verbalization, and instructions. Psychonomic Science, 1967, 8, 311-312.

CARMEAN, S. L., \& WEIR, M. W. Effects of verbalizations on discrimination learning and retention. Journal of Verbal Learning \& Verbal Behavior, 1967, 6, 545-550.

DEESE, J., \& HULSE, S. H. The psychology of learning. (Rev. ed.) New York: McGraw-Hill, 1967.

HALL, J. F. The psychology of learning. Philadelphia: Lippincott, 1966. NOTE

1. This research was supported in part by Grant MH 15848-01 from the National Institute of Mental Health. The results were part of a paper presented at the 1969 meeting of the Midwestern Psychological Association, Chicago, Illinois. I thank the administration and faculty of the Bellingham Public Schools for their courtesy and cooperation. 